Int. J. Electrochem. Sci., 16 (2021) Article ID: 210756

\title{
Preparation of Vapor Grown Carbon Fiber/2-((4- dimethylamino) phenyl) amino) naphthalene-1, 4-dione Composites and their supercapacitor properties
}

\author{
Latifatu Mohammed ${ }^{1, *}$, Hu Mengyang ${ }^{2}$, Hamenu Louis ${ }^{3}$, Alfred Madzvamuse ${ }^{4}$, Andrew Nyamful ${ }^{5}$, \\ David Dodoo-Arhin ${ }^{6}$, Andrews Danquah ${ }^{7}$, Odoi King Manteaw ${ }^{8}$, Mohammed Nafiu Zainudeen ${ }^{5}$, \\ Samuel Agyekum Darkwa ${ }^{5}$ Jeong Ho Park ${ }^{2}$, Jang Myoun $\mathrm{Ko}^{2}$
}

${ }^{1}$ Division of Sustainable Energy Technologies, Council for Scientific and Industrial Research-Institute of Industrial Research, P. O. Box LG 587, Ghana

${ }^{2}$ Department of Applied Chemistry \& Biotechnology, Hanbat National University, 125 Dongseodaero, Deokmyeong-dong, Yuseong-gu, Daejeon, South Korea.

${ }^{3}$ Department of Chemistry, School of Physical and Mathematical Sciences, College of Basic and Applied Sciences University of Ghana, Legon, Ghana.

${ }^{4}$ Department of Chemistry, University of Zimbabwe, P. O. MP 167, Mount Pleasant, Harare, Zimbabwe

${ }^{5}$ Department of Nuclear Engineering, Graduate School of Nuclear and Allied Sciences, University of Ghana, Ghana

${ }^{6}$ Department of Materials Science \& Engineering, University of Ghana, Annie Jiaggie Road, LegonAccra, Ghana.

${ }^{7}$ Department of Molecular Biology and Biotechnology, University of Cape Coast, Cape coast

${ }^{8}$ Biotechnology and Nuclear Agricultural Research Institute, Ghana Atomic Energy Commission, Ghana

*E-mail: latifatu.mohammed@yahoo.com

doi: $10.20964 / 2021.07 .51$

Received: 11 February 2021 / Accepted: 9 April 2021 / Published: 31 May 2021

In this work, a derivative of 1,4-dihydoxynaphthalene, 2-((4-dimethylamino) phenyl) amino) naphthalene-1,4-dione (HBU) was synthesized by reacting 1,4-dihydoxynaphthalene with $\mathrm{N}, \mathrm{N}$ Dimethyl-p-phenylenediamine. The supercapacitive properties of the electrodes containing various weights percent of vapor grown carbon fiber (VGCF) and HBU were probed in terms of redox behavior, the effect of VGCF, and specific capacitance. The VGCF created an excellent electronic pathway in the electrode, boosting the redox transition reaction in HBU involving a total of three-electron (3e-)-threeproton $\left(3 \mathrm{H}^{+}\right)$processes corresponding to 2,3-dihydro1,4-naphthoquinone-1,4-dihydroxynaphthalene and the aliphatic amine in the backbone of the substituted derivative of aniline. This led to a higher specific capacitance of $98 \mathrm{~F} / \mathrm{g}$ for the HBU-VGCF electrode with a higher weight percent of HBU. The 
capacity retention of about $57 \%$ was observed for the HBU-VGCF electrodes after the $1000^{\text {th }}$ cycle owing to the VGCF supporting the HBU by stabilizing its redox activity.

Keywords: vapor grown carbon fiber, 1, 4-dihydoxynaphthalene, electrode, supercapacitor

\section{$\underline{\text { FULL TEXT }}$}

(C) 2021 The Authors. Published by ESG (www.electrochemsci.org). This article is an open access article distributed under the terms and conditions of the Creative Commons Attribution license (http://creativecommons.org/licenses/by/4.0/). 